ROCZNIKI HUMANISTYCZNE

Tom LXIX, zeszyt $8-2021$

DOI: https://doi.org/10.18290/rh21698-5

ALBA MARÍA GÁLVEZ VIDAL
MANUEL SEVILLA MUÑOZ

\title{
LOS LÍMITES DIFUSOS ENTRE COMPUESTOS SINTAGMÁTICOS, COLOCACIONES Y LOCUCIONES
}

\author{
La gran paradoja de la Fraseología consiste en haber intentado \\ acotar una parcela lingüística discreta y haber utilizado, sin \\ embargo, categorías radicalmente difusas
}

(Montoro 141)

\section{THE DIFFUSE DELIMIT BETWEEN SYNTAGMATIC COMPOUNDS, COLLOCATIONS AND LOCUTIONS}

\begin{abstract}
Syntagmatic compounds (CS) are not easy to distinguish from other fixed syntagmas such as collocations and nominal expressions, since there are many similarities between them from the formal, semantic and functional approaches. Thus, it is possible to find the same syntagma classified as a nominal expression, a collocation and a CS depending on the lexicographical or phraseographical work consulted (mano dura, for instance). García-Page (En torno a, "Hombre rana"), among other authors, has shown his concern for these similarities; Osorio and Serra have made a proposal to distinguish between nominal expressions and CS; Corpas (51) establishes a difference between collocations and nominal expressions according to their process of fixation. This paper aims to delimit the concept of CS in contrast to collocations and nominal expressions from a phraseological approach, on the basis of Pamies' theory, who considers CS as phraseological units (PU). In order to do so, we propose two criteria regarding the fixation process of CS: that they have been artificially coined due to the need to name an ontological reality for the first time, and that this need arises in a specialised field of knowledge. We test the validity of these two criteria on a corpus of fixed syntagmas drawn from three Spanish novels.
\end{abstract}

Key words: syntagmatic compound; nominal expression; collocation; phraseology.

Alba María GÁlvez-VIDAL - Departamento de Idiomas, Universidad Católica de Murcia, España; e-mail: amgalvez@ucam.edu; ORCID: https://orcid.org/0000-0002-5512-8816.

Manuel Sevilla MuÑOZ - Departamento de Traducción e Interpretación, Universidad de Murcia, España; e-mail: masevilla@um.es; ORCID: https://orcid.org/0000-0002-3450-9708. 


\section{INTRODUCCIÓN}

Los compuestos sintagmáticos (CS) son sintagmas fijos muy estudiados en el campo de la terminología y, recientemente también desde la fraseología, pues, a pesar de no haber sido considerados inicialmente como unidades fraseológicas (UF), presentan características similares a UF sintagmáticas, como locuciones y colocaciones, desde un punto de vista formal, semántico $\mathrm{y}$ funcional.

El fraseólogo García-Page («Introducción» 24) plantea los parecidos entre los CS y las UF sintagmáticas desde la fraseología, aunque niega que los CS formen parte de la familia fraseológica e intenta distinguir entre CS, colocaciones y locuciones (En torno a, «Hombre rana»). Sanz (307-310), desde el campo de la terminología, también aprecia esas mismas semejanzas y opina que hay argumentos suficientes tanto para considerar que los CS son UF como para razonar que no lo son.

Corpas (51) distingue las colocaciones de las locuciones en función de su proceso de fijación: las colocaciones se fijan en la norma y las locuciones en el uso. Esta autora no hace ninguna mención a los CS porque los excluye de la fraseología, precisamente por su proceso de formación. Osorio y Serra elaboran una propuesta para diferenciar locuciones de CS basándose en la existencia o no de sinónimos, lo que está relacionado con la formación de ambos sintagmas.

Sobre esta base, pretendemos dar un paso más en la delimitación de las tres estructuras sintagmáticas fijas: CS, colocaciones y locuciones. Pensamos que el proceso de fijación marca la diferencia entre estos tres tipos de sintagmas y que es posible establecer unos criterios tomando como referencia dicho proceso. Para poder llevar a cabo este estudio, contamos con un corpus de 385 sintagmas fijos extraídos de tres novelas del neorrealismo español.

\section{SIMILITUDES ENTRE CS, LOCUCIONES Y COLOCACIONES}

Buena parte de las dudas existentes al establecer unos límites definidos para diferenciar entre sí CS, locuciones y colocaciones radica en un conjunto de características de tipo formal, funcional y fraseológico compartidas por estas tres unidades lingüísticas, lo que da lugar, en ocasiones, a que un mismo sintagma se clasifique de distinta manera en función de la obra léxica consultada; así ocurre, por ejemplo, con mano dura, nombre de pila, fuerza 
de voluntad, primera línea y punto de vista, documentados como CS (RAE), locuciones nominales (Seco, Andrés y Ramos) y colocaciones (Bosque).

Desde un punto de vista formal, y teniendo en cuenta que todos los CS de nuestro corpus tienen función de sustantivo, nos encontramos ante sintagmas nominales con estructuras similares. Corpas (67-76) clasifica las colocaciones en función de la composición de estas estructuras, igual que hacen Clavería y Torruella (ctd. en Sager 327-329) con los CS.

Desde un punto de vista funcional, las locuciones se han clasificado tradicionalmente según categorías gramaticales, debido a que una locución cumple una función similar a la de una palabra. Corpas, la RAE (Diccionario) y Seco, Andrés y Ramos siguen este sistema. Barrios, Gálvez (La función de) y otros autores también consideran las colocaciones por categoría gramatical. En este sentido, las locuciones y las colocaciones nominales, igual que los CS de nuestro corpus, cumplen la función de un sustantivo.

Las obras lexicográficas suelen incluir CS y locuciones aportando información de tipo léxico:

- Definición. En el DLE, la cuarta acepción de pata de gallo, por ejemplo, es «Arruga con surcos divergentes que con los años se forma en el ángulo externo de cada ojo».

- Género para locuciones nominales y CS con función de sustantivo: la locución el más allá es masculina y el compuesto sintagmático corona de laurel es femenino.

- El registro: la locución adjetiva de narices se etiqueta como coloquial y la locución adjetiva de cojones como malsonante, además de coloquial, en el $D L E$ y en Seco, Andrés y Ramos.

- La disciplina en la que se pueden incluir tanto locuciones como CS especializados: el compuesto ancla de leva y la locución verbal apear el ancla, por ejemplo, se incluyen dentro del campo marina en el DLE.

Las colocaciones, sin embargo, no aparecen en las entradas de las obras léxicas, aunque ocasionalmente se incluyen como ejemplos de uso de una palabra. En el $D L E$, se define empedernido como "Obstinado, tenaz, que tiene un vicio o una costumbre muy arraigados» y se aporta como ejemplo de uso el sintagma fumador empedernido, una colocación que se podría definir, partiendo de la definición de empedernido, como persona que tiene muy arraigado el vicio o la costumbre de fumar. Realmente, como ya hemos comentado, las colocaciones cumplen la función de una palabra, por lo que también se les podría dar el mismo tratamiento en los diccionarios que a las locuciones y a los CS. 
Desde un punto de vista fraseológico, estos tres tipos de sintagmas también presentan similitudes destacables. Corpas (20) estableció las tres características consideradas hasta la fecha como definitorias de las UF: la multilexicalidad, la idiomaticidad (en grado variable) y la fijación (en grado variable).

Sin duda, los CS están formados por más de una palabra gráfica, igual que locuciones y colocaciones, por lo que cumplen la característica de multilexicalidad. En cuanto a la fijación, estas unidades presentan un elevado nivel de fijación, tanto semántica como formal, pues poseen un sentido único, son inmodificables y sus elementos constitutivos son insustituibles. Algunos ejemplos de CS con fijación absoluta son cuatro gatos, lucero del alba, patas de gallo; no obstante, y teniendo en cuenta que son sustantivos, algunos admiten variación de número: plaza de toros (plazas de toros), bomba de mano (bombas de mano), paga extra (pagas extra). A este respecto, Gómez Molina hace la siguiente consideración: «[...] los compuestos se encuentran entre las colocaciones y las locuciones, ya que presentan mayor grado de fijación e idiomaticidad que las primeras, pero menos que las segundas» (Molina et Ramon 16).

Por último, los CS presentan un grado variable de idiomaticidad, desde la literalidad propia de las colocaciones hasta la más opaca idiomaticidad de muchas locuciones: «Los compuestos sintagmáticos suelen ser transparentes [...], si bien algunos lo son parcialmente» (RAE, Nueva gramática 743). Así, por ejemplo, una mala idea es, efectivamente, una mala intención, lo que coincide literalmente con la quinta acepción de idea en el DLE: «Intención de hacer algo». Por otra parte, el compuesto papel de barba («papel de tina, que no está recortado por los bordes», según el $D L E$ ) presenta una idiomaticidad evidente.

Teniendo en cuenta todos estos puntos de encuentro entre CS, colocaciones nominales y locuciones nominales, no es de extrañar que exista cierta dificultad para distinguir unos sintagmas de otros.

\section{DIFERENCIAS ENTRE CS, LOCUCIONES Y COLOCACIONES}

La diferencia fundamental entre estas tres estructuras sintagmáticas reside en la manera de formarse y fijarse en la lengua. Corpas atiende a este criterio para establecer el límite entre colocaciones y locuciones: «UFS que constituyen unidades en el sistema y UFS que, desde el punto de vista del sistema, son sintagmas completamente libres, generados a partir de reglas, pero que, 
al mismo tiempo, presentan una fijación determinada por el uso» (51); de este modo, las colocaciones se fijan en la norma, mientras que las locuciones se fijan en el sistema.

Frente a esta diferenciación entre colocaciones y locuciones desde el punto de vista de su proceso de fijación, «el concepto de compuesto sintagmático no responde a hechos internos al sistema sino a un criterio puramente designativo» (Pérez 307), estableciéndose una estrecha relación entre el compuesto y el referente designado; la formación de los compuestos «responde a una necesidad de dar nombre, [esto es], de cubrir una laguna denominativa» (Ferrando ctd. en Osorio Olave y Serra Sepúlveda 113). Es decir, los CS se sitúan en el eje sincrónico de la lengua, frente a locuciones y colocaciones, que son el resultado de la repetición diacrónica, la cual da lugar a su fijación. En resumen, los CS son creaciones artificiales de los hablantes de una lengua que se han visto en la necesidad de nombrar algo para lo cual no existía previamente una denominación.

Para la mayoría de los fraseólogos, los CS no constituyen una rama más del árbol fraseológico, pues asimilan su creación y fijación a un proceso de composición de palabras; no obstante, Pamies lleva a cabo una revisión del concepto de multilexicalidad en relación con los CS, que conduce a su aceptación como UF. En esta misma línea, Solano, en su clasificación de las UF, incluye los «compuestos disociados» como parte de la fraseología, aunque los considera dentro del grupo de las locuciones. Osorio y Serra, Gálvez y Navarro («¿Es Carmen?»), Sevilla, Gálvez (La función de) y Toledo y Martínez dan un paso más y tratan los CS como un subgrupo fraseológico con características propias, dentro del conjunto de UF.

Así, se observan dos implicaciones directamente derivadas del proceso de creación y fijación de los CS, una relacionada con la motivación y otra con el ámbito en el que surgen; ambas acentúan la diferencia con las colocaciones y las locuciones.

Tal como hemos comentado, el CS surge de la necesidad de nombrar por primera vez una nueva realidad ontológica (un objeto o un concepto), por lo que existe una relación estrecha entre la formulación del compuesto y la naturaleza de la realidad nombrada. De este modo, los compuestos pueden ser descripciones o explicaciones de la forma (lentes de pinza), la composición (corona de laurel), la función (goma de borrar) de un objeto, así como descripciones o explicaciones de un concepto (sesión continua).

Por otra parte, la necesidad de nombrar nuevas realidades surge en ámbitos académicos o profesionales en los que se estudian, diseñan, fabrican o utilizan estas nuevas realidades. Buena prueba de ello es que nuestro 
corpus de CS de partida, extraído de tres novelas, consta de 67 elementos diferentes (109 ocurrencias, incluyendo las repeticiones), mientras que en un solo prospecto de medicamento (texto especializado) podemos localizar 15-40 CS diferentes, 40-80 ocurrencias totales (Álvarez 75-76).

Aunque es cierto que también hay colocaciones y locuciones especializadas, lo que queda patente en estudios como el de Toledo y Martínez, también se observa un gran número de estas unidades en el lenguaje no especializado; sin embargo, los CS tienen su origen en un ámbito concreto del conocimiento.

De este modo, la motivación de un sintagma nominal, que se crea por la necesidad de nombrar por primera vez una realidad ontológica mediante una descripción o explicación, y el hecho de que dicho sintagma se haya generado en un ámbito profesional o académico concreto, se pueden tomar como indicadores que permitan distinguir un CS de una colocación o una locución.

\section{OBJETIVOS Y METODOLOGÍA}

El objetivo de este trabajo es establecer unos criterios claros para diferenciar los CS frente a las colocaciones o locuciones nominales. En este sentido, y de acuerdo con el marco teórico de este artículo, planteamos como hipótesis que, si un sintagma fijo surge por la necesidad de nombrar por primera vez una realidad ontológica en un ámbito especializado, dicho sintagma es un CS.

Con el fin de confirmar o refutar la hipótesis formulada y alcanzar el objetivo enunciado, planteamos un estudio de casos para comprobar la validez de los dos criterios de diferenciación: la necesidad de generar por primera vez una denominación para una realidad ontológica y que esta nueva denominación surja en un ámbito especializado. Aplicamos el estudio de casos a la totalidad de CS extraídos de un corpus de textos literarios conformado por tres novelas del neorrealismo español:

- La colmena, de Camilo José Cela (1979)

- Entre visillos, de Carmen Martín Gaite (1992)

- Cinco horas con Mario, de Miguel Delibes (1978).

Los textos escogidos responden a dos criterios. Por un lado, pertenecen al género literario con el fin de alejarnos de los textos especializados, en los que los CS son abundantes y claramente distinguibles de otras unidades léxicas parecidas. Precisamente, los CS que aparecen en textos no especializados son aquellos que pueden plantear una mayor dificultad en su clasificación por el hecho de utilizarse en un lenguaje no especializado. Por otra parte, los tres textos escogidos pertenecen al movimiento estético del realismo, cuyo 
objetivo estético era representar la realidad de la forma más fiel posible, por lo que la lengua recogida en ellos resulta bastante representativa de un uso común y contemporáneo del español.

Para la extracción de los CS de los tres textos del corpus, se han seguido los siguientes pasos.

- Extracción de todos los sintagmas fijos de los tres textos mediante la aplicación de nuestra competencia fraseológica activa y pasiva.

- Comprobación de cada uno de los sintagmas seleccionados en las siguientes obras lexicográficas y fraseográficas:

- DLE (RAE), en el que documentamos CS.

- REDES (Bosque), que utilizamos como diccionario de colocaciones.

- Diccionario fraseológico del español actual (Seco, Andrés y Ramos), como diccionario de locuciones.

De este modo, hemos recopilado un total de 385 ocurrencias entre las tres novelas.

- Asignación de un ámbito en el que se ha podido acuñar el sintagma, si es el caso. Para ello, hemos consultado las definiciones de los sintagmas fijos en el $D L E$ y en otras obras lexicográficas y fraseográficas con el fin de identificar los conceptos y las realidades ontológicas representadas por estos sintagmas y su relación con ámbitos académicos o profesionales concretos.

- Selección de todos los sintagmas encontrados en el $D L E$ y de otros sintagmas no incluidos en esta fuente, pero que guardan relación con un ámbito especializado. Hemos descartado el resto de sintagmas, pues no cumplen los criterios que pretendemos poner a prueba en este estudio.

- Ordenación de los sintagmas seleccionados en una tabla con la siguiente información:

- Sintagma en su forma canónica.

- Presencia o no en las tres obras lexicográficas y fraseográficas consultadas. Es de destacar que, en algunos casos, no hemos encontrado el sintagma, tal como aparece en las novelas, pero sí sintagmas formal y semánticamente similares, lo que hemos indicado en la tabla.

- Ámbito asignado, en su caso.

A continuación, incluimos la tabla resultante de este proceso, la cual ha servido de base para el estudio que llevamos a cabo en este artículo. 
Tabla 1. Potenciales CS extraídos del corpus de novelas

\begin{tabular}{|c|c|c|c|c|}
\hline Sintagma & $D L E$ & REDES & Seco & Ámbito \\
\hline abrigo de pieles & & & & Moda \\
\hline agua corriente & $\mathrm{X}$ & $\mathrm{X}$ & & Decoración/Arquitectura \\
\hline ama de cría & $\mathrm{X}$ & & & \\
\hline Año Nuevo & $\mathrm{X}$ & $\mathrm{X}$ & & Calendario \\
\hline artículo de fondo & $\mathrm{X}$ & & de fondo & Periodismo \\
\hline boca de riego & $\mathrm{X}$ & & & Jardinería \\
\hline bomba de mano & $\mathrm{X}$ & de mano & de mano & Militar \\
\hline buen humor & $X$ & $\mathrm{X}$ & & \\
\hline cabeza de chorlito & $\mathrm{X}$ & & $\mathrm{X}$ & \\
\hline café con leche & & & $\mathrm{X}$ & Gastronomía \\
\hline café solo & $\mathrm{X}$ & & & Gastronomía \\
\hline cama turca & $\mathrm{X}$ & & & Decoración/Arquitectura \\
\hline carne de gallina & $\mathrm{X}$ & & $\mathrm{X}$ & \\
\hline coche de línea & $\mathrm{X}$ & de línea & & Transporte \\
\hline contrato de trabajo & & & & Relaciones laborales \\
\hline corona de laurel & $\mathrm{X}$ & $\begin{array}{l}\text { coronar de } \\
\text { laurel }\end{array}$ & & \\
\hline corrida de toros & $\mathrm{X}$ & & & Tauromaquia \\
\hline cuadro de mandos & $\mathrm{X}$ & & & Ingeniería \\
\hline cuarto de baño & $\mathrm{X}$ & & & Decoración/Arquitectura \\
\hline cuarto de estar & $\mathrm{X}$ & & & Decoración/Arquitectura \\
\hline cuatro gatos & $\mathrm{X}$ & & $\mathrm{X}$ & \\
\hline cuenta corriente & $\mathrm{X}$ & $\mathrm{X}$ & & Economía \\
\hline facilidad de palabra & $\mathrm{X}$ & & & \\
\hline fuerza de voluntad & $\mathrm{X}$ & $\mathrm{X}$ & $\mathrm{X}$ & \\
\hline gente bien & $\mathrm{X}$ & & & \\
\hline goma de borrar & $\mathrm{X}$ & & & Papelería \\
\hline guerra civil & $\mathrm{X}$ & $\mathrm{X}$ & & Militar \\
\hline hijo de Dios & $\mathrm{X}$ & & & \\
\hline
\end{tabular}




\begin{tabular}{|c|c|c|c|c|}
\hline hijo de familia & $\mathrm{X}$ & & & \\
\hline hilo de voz & $\mathrm{X}$ & & & \\
\hline juego floral & $\mathrm{X}$ & & & Rituales \\
\hline legítima defensa & $\mathrm{X}$ & $\mathrm{X}$ & & Derecho \\
\hline lente de pinza & & & & Óptica \\
\hline Ley de Dios & $\mathrm{X}$ & & & Religión \\
\hline lucero del alba & $\mathrm{X}$ & & $\mathrm{X}$ & \\
\hline madre de familia & $\mathrm{X}$ & & & \\
\hline mal educada & $\mathrm{X}$ & & & \\
\hline mal humor & $\mathrm{X}$ & $\mathrm{X}$ & & \\
\hline mala idea & $\mathrm{X}$ & $\mathrm{X}$ & & \\
\hline mano dura & $\mathrm{X}$ & $\mathrm{X}$ & $\mathrm{X}$ & \\
\hline media vuelta & $\mathrm{X}$ & & & \\
\hline mesilla de noche & $\mathrm{X}$ & de noche & de noche & Decoración/Arquitectura \\
\hline misa cantada & $X$ & $\mathrm{X}$ & cantar misa & Religión \\
\hline nombre de pila & $\mathrm{X}$ & $\mathrm{X}$ & $\mathrm{X}$ & Administración \\
\hline noticia bomba & $\mathrm{X}$ & & & \\
\hline ojo clínico & $\mathrm{X}$ & $\mathrm{X}$ & $\mathrm{X}$ & \\
\hline padre de familia & $\mathrm{X}$ & & & \\
\hline paga extraordinaria & $\mathrm{X}$ & & & Relaciones laborales \\
\hline papel de barba & $\mathrm{X}$ & & & Papelería \\
\hline papel de fumar & $\mathrm{X}$ & & & Tabaco \\
\hline pata de gallo & $\mathrm{X}$ & & & \\
\hline plaza de toros & $\mathrm{X}$ & & $\mathrm{X}$ & Tauromaquia \\
\hline primera línea & $\mathrm{X}$ & $\mathrm{X}$ & $\mathrm{X}$ & \\
\hline punto de vista & $\mathrm{X}$ & $\mathrm{X}$ & $\mathrm{X}$ & \\
\hline quebradero de cabeza & $\mathrm{X}$ & $\mathrm{X}$ & & \\
\hline rosa de los vientos & $\mathrm{X}$ & & & Cartografía/Geografía \\
\hline sala de espera & & $\mathrm{X}$ & & Decoración/Arquitectura \\
\hline sentido del humor & $\mathrm{X}$ & $\mathrm{X}$ & & \\
\hline sesión continua & $\mathrm{X}$ & $\mathrm{X}$ & $\begin{array}{l}\text { (de) sesión } \\
\text { continua }\end{array}$ & Cine \\
\hline
\end{tabular}




\begin{tabular}{|c|c|c|c|c|}
\hline sociedad anónima & $\mathrm{X}$ & $\mathrm{X}$ & & Economía \\
\hline sombrero de ala ancha & & & & Moda \\
\hline todo hijo de vecino & $\mathrm{X}$ & & & Calendario \\
\hline Todos los Santos & & & & Moda \\
\hline traje de noche & $\mathrm{X}$ & & de noche & \\
\hline vino tinto & $\mathrm{X}$ & $\begin{array}{c}\text { visita de } \\
\text { cortesía }\end{array}$ & de cumplido & \\
\hline visita de cumplido & & & & \\
\hline
\end{tabular}

A partir de esta tabla, llevamos a cabo un estudio de casos en el que se ha comprobado si los dos criterios mencionados anteriormente son suficientes para diferenciar un compuesto sintagmático de una colocación y de una locución.

En la tabla observamos diferentes situaciones:

1. Sintagma incluido solo en el $D L E$, al que no hemos podido asignar un ámbito.

2. Sintagma incluido solo en el $D L E$, al que hemos podido asignar un ámbito.

3. Sintagma incluido en el $D L E$ y alguna de las otras dos obras, al que no hemos podido asignar un ámbito.

4. Sintagma incluido en el $D L E$ y alguna de las otras dos obras, al que hemos podido asignar un ámbito.

5. Sintagma incluido en las tres obras, al que no hemos podido asignar un ámbito.

6. Sintagma incluido en las tres obras, al que hemos podido asignar un ámbito.

7. Sintagma no incluido en el $D L E$, pero sí en alguna de las otras dos obras, al que hemos podido asignar un ámbito.

8. Sintagma no incluido en ninguna de las tres obras, al que hemos podido asignar un ámbito.

Para cada una de estas ocho situaciones, hemos analizado uno o dos casos desde un punto de vista cualitativo para comprobar la validez de la hipótesis formulada. 


\section{RESULTADOS Y DISCUSIÓN}

En la Tabla 1 se recoge un total de 67 sintagmas, todo ellos incluidos en el DLE como CS exceptuando café con leche, lentes de pinza, vino tinto, contrato de trabajo, abrigos de pieles, sala de espera, sombrero de ala ancha y Todos los Santos que, por sus circunstancias formales, funcionales y semánticas, son similares a otras unidades que sí están recopiladas en el $D L E$ (como café solo, lentes de contacto, vino rosado, etc.).

A continuación, llevamos a cabo el estudio de casos de acuerdo con la tipología establecida en la metodología:

1. Sintagma incluido únicamente en el $D L E$, al que no hemos podido asignar un ámbito, es decir, un sintagma que, de acuerdo con la RAE, debería ser considerado CS. Es el caso, por ejemplo, de ama de cría. En el DLE, se trata como sinónimo de la palabra ama, definida en su $9^{a}$ acepción como «Mujer que amamanta a una criatura ajena», lo cual nos lleva a pensar que el sintagma ama de cría no se creó de forma artificial debido a la necesidad de nombrar una nueva realidad ontológica; además, existe el término nodriza, también sinónimo de ama, según el $D L E$. De este modo se incumple el primero de nuestros criterios. Por otra parte, este sintagma no parece haberse formado en un ámbito especializado, por lo que tampoco cumple el segundo criterio, sino que más bien se ha fijado en la norma para diferenciar este significado de la palabra ama de otros sentidos de la misma palabra, mecanismo que también se ha aplicado a ama de llaves. Algo parecido ocurre con la palabra banco («Conjunto de peces que van juntos en gran número», $D L E$ ) y la colocación banco de peces (REDES): la colocación tiene el mismo significado que la palabra a partir de la cual se forma. Por todo ello, consideramos que este sintagma se forma a partir de la palabra ama y se fija en la norma con un sentido literal, lo que se corresponde con una colocación nominal, a pesar de no estar recogida en el diccionario REDES.

2. Sintagma incluido solo en el $D L E$, al que hemos podido asignar un ámbito. Es el caso de rosa de los vientos, sintagma con el que se designa la siguiente realidad ontológica, sin que haya ninguna otra denominación para la misma: "Círculo que tiene marcados alrededor los 32 rumbos en que se divide la vuelta del horizonte» $(D L E)$ y que empezó a usarse en el siglo XVI en las cartas de navegación, por lo que su origen aparece asociado a un ámbito especializado, como es el de la cartografía, dentro de la geografía. Así, nos encontramos ante un sintagma utilizado para nombrar una realidad ontológica por primera vez en un ámbito concreto, por lo que cumple los dos 
criterios propuestos. Tiene un sentido idiomático, de manera que no se trata de una colocación, y no se ha fijado por el uso, así que tampoco es una locución; se trata de un compuesto sintagmático.

3. Sintagma incluido en el $D L E$ y alguna de las otras dos obras, al que no hemos podido asignar un ámbito, es decir, son sintagmas cuya clasificación en las obras lexicográficas y fraseográficas es confusa. Es el caso de cuatro gatos, recogido como CS en el DLE («poca gente y sin importancia») y como locución nominal en el Diccionario fraseológico de Seco, Andrés y Ramos («muy poca gente»). Con estas definiciones, se antoja muy improbable que haya surgido la necesidad de acuñar de forma artificial este sintagma en un ámbito concreto para nombrar una realidad ontológica por primera vez; más bien parece haberse fijado en la lengua por el uso, o sea, ha seguido el sistema de fijación propio de las locuciones (Corpas 51), por lo que no cumple el primero de nuestros criterios. Al tener un significado idiomático, queda descartada la posibilidad de tratarse de una colocación. En definitiva, este sintagma no cumple ninguno de los dos criterios, es idiomático y parece haberse fijado por el uso, por lo que nos inclinamos a considerarlo como locución nominal.

Otro ejemplo de este caso es el de mal humor. El significado de este sintagma, que está recogido en el $D L E$, como CS, y en el REDES, como colocación, es «Actitud o disposición negativa e irritada» $(D L E)$. Teniendo en cuenta la $3^{\mathrm{a}}$ acepción de humor en el $D L E$, «Disposición en que alguien se halla para hacer algo», observamos que el significado de mal humor es composicional, es decir, el sintagma se forma a partir de la palabra, por lo que no se ha acuñado de forma artificial para nombrar por primera vez una realidad ontológica (incumple los dos criterios). Dicho con otras palabras, este sintagma se ha fijado en la norma, por lo que debe ser considerado como una colocación nominal.

4. Sintagma incluido en el $D L E$ y alguna de las otras dos obras, al que hemos podido asignar un ámbito. Es el caso, por ejemplo, de Sociedad Anónima, incluido en el $D L E$ y en el REDES. Tras leer su definición, «sociedad que se forma por acciones, con responsabilidad circunscrita al capital que estas representan» $(D L E)$, es fácil asociar este sintagma al ámbito del comercio y la economía, en el que se utiliza para referirse a una realidad ontológica que no cuenta con ninguna otra denominación, por lo que se ha generado de forma artificial por la necesidad de nombrar por primera vez dicha realidad ontológica. En este sentido, cumple los dos criterios y debería ser considerado como CS y no como colocación nominal. 
5. Sintagma incluido en las tres obras, al que no hemos podido asignar un ámbito. Es el caso de sintagmas como ojo clínico, definido como "perspicacia o sagacidad» $(D L E)$ y «facilidad para captar una circunstancia o preverla» (Seco et al.). Aunque la acepción $20^{\mathrm{a}}$ de ojo, «aptitud singular para apreciar certera y fácilmente las circunstancias que concurren en algún caso o para calcular magnitudes» parece coincidir con la definición del sintagma, el significado de la palabra clínico no coincide con el sentido de este, es decir, el significado de ojo clínico no es composicional, por lo que queda descartada la posibilidad de que se trate de una colocación. Por otra parte, y a pesar de la presencia de la palabra clínico, no se puede asociar el sintagma ni a la medicina ni a ningún otro ámbito especializado; se trata de un concepto general, aplicable a situaciones muy diversas, por lo que su fijación responde más al uso que a la necesidad de nombrar por primera vez una realidad ontológica. Teniendo en cuenta el incumplimiento de los dos criterios, la idiomaticidad de este sintagma y el proceso de fijación seguido, lo clasificamos dentro del grupo de las locuciones nominales.

6. Sintagma incluido en las tres obras, al que hemos podido asignar un ámbito. Es el caso de nombre de pila, definido como «nombre que se da a la criatura cuando se bautiza o el que se le adjudica por elección para identificarla junto a los apellidos» (DLE) y «nombre personal que precede al apellido y que a los cristianos se les impone en el bautismo» (Seco et al.). En las dos fuentes observamos que se trata del nombre que se otorga a una persona en el bautismo, ceremonia que se incluye en el sintagma con la palabra pila (pila bautismal); así, el nombre de pila es el nombre que se impone a una persona en la pila bautismal. A pesar de la referencia religiosa, esta denominación se utiliza con fines administrativos y no religiosos, como una manera de diferenciar el nombre del apellido. De este modo, el sintagma nombre de pila se acuñó de forma artificial en el ámbito administrativo para nombrar una realidad por primera vez (el nombre que se impone en la pila bautismal). Cumple los dos criterios y lo consideramos un CS.

7. Sintagma no incluido en el $D L E$, pero sí en alguna de las otras dos obras, al que hemos podido asignar un ámbito. El sintagma sala de espera se encuentra en esta situación, pues está incluido en $R E D E S$, pero no en el $D L E$, a pesar de que otros sintagmas similares como sala de fiestas, sala de estar, cuarto de estar y cuarto de baño sí se incluyen en este último diccionario. Tanto sala, como cuarto se refieren a una habitación, de modo que una sala de espera es una sala en la que se espera, igual que un cuarto de baño es un cuarto para el baño, es decir, estamos ante sintagmas con un significado 
composicional. Ya comentamos en el marco teórico que los CS pueden ser literales o idiomáticos, por lo que la duda que se plantea ahora es si nos encontramos ante un CS o una colocación, es decir, si el sintagma se ha fijado en la norma o si se ha creado de forma artificial. En este caso, no hay ninguna otra denominación para una sala de espera y esta realidad ontológica es propia de la decoración o la arquitectura, por lo que cabría pensar que se trata de un CS, pero cuesta justificar que no estamos ante una colocación, por lo que dejamos abierto un interrogante, aunque nos inclinamos a pensar que sí es un CS.

Otro ejemplo de esta situación es café con leche que se encuentra recogido en el diccionario fraseológico de Seco et al. con el significado «color marrón claro semejante al del café con leche». En la novela se utiliza para nombrar la bebida, por lo que este significado no es válido para este sintagma del corpus. Curiosamente, en el DLE, no se incluye café con leche, pero sí café solo, café descafeinado, café americano, café irlandés, café de puchero. Este sintagma con significado literal parece haberse creado de forma artificial para nombrar una realidad ontológica por primera vez en el ámbito de la gastronomía, igual que con los nombres de los otros tipos de café. El cumplimiento de nuestros criterios nos lleva a pensar que café con leche debería ser considerado también un CS.

8. Sintagma no incluido en ninguna de las tres obras, al que hemos podido asignar un ámbito. Es el caso de lentes de pinza que no se encuentra recogido en el $D L E$, a pesar de que sí encontramos en él expresiones similares, como lentes de contacto. Este sintagma parece haberse acuñado para denominar por primera vez una realidad ontológica (las lentes que se ajustan en la nariz con una pinza) en los ámbitos de la óptica y la oftalmología, por lo que cumple los dos criterios. Se trata de un caso similar al de sala de espera, pero el hecho de que la realidad nombrada con el sintagma lentes de pinza sea poco conocida, le otorga un mayor grado de especialización, lo que favorece su clasificación como CS.

\section{CONCLUSIONES}

El objetivo de este estudio era establecer unos criterios claros para diferenciar los CS frente a las colocaciones o locuciones nominales dentro del ámbito fraseológico a partir del estudio de un corpus extraído de tres novelas españolas. 
Para ello, en la primera parte de nuestro estudio hemos expuesto las similitudes de los tres tipos de sintagmas a nivel formal, funcional y fraseológico, evidenciando así la dificultad existente en muchos casos para diferenciarlas hasta el punto de que podemos encontrar un mismo sintagma clasificado en diferentes fuentes lexicográficas o fraseográficas de distinta manera. A continuación, hemos expuesto las diferencias existentes entre estos sintagmas, que residen, fundamentalmente, en la manera en la que se han fijado en la lengua, a saber: las colocaciones y las locuciones se fijan en la norma y en el sistema respectivamente, de acuerdo con Corpas (51); mientras que los CS parecen ser creaciones artificiales que surgen de la necesidad de nombrar por primera vez una nueva realidad ontológica en un ámbito especializado.

Con el fin de confirmar o refutar esta hipótesis sobre el origen de los compuestos, se ha llevado a cabo un estudio de casos a partir de un corpus de CS extraído de tres novelas. Para ello, aplicamos nuestra competencia fraseológica para localizarlos, los recogimos en una tabla y los documentamos con fuentes lexicográficas y fraseográficas tomando como fuente principal el DLE de la RAE, pero, también, el REDES y el Diccionario fraseológico de Seco et al. Una vez recogidos, aplicamos sistemáticamente los dos criterios propuestos a los 67 sintagmas recogidos y expusimos algunos ejemplos escogidos para las ocho situaciones encontradas en el corpus. La aplicación de los criterios ha resultado válida para nuestro corpus y, de acuerdo con ellos, consideramos únicamente 38 de los 67 sintagmas como CS.

Así, hemos constatado que los criterios propuestos son válidos para distinguir la mayoría de los CS de otros sintagmas fraseológicos, como las colocaciones o locuciones nominales, en nuestro corpus, aunque es cierto que la hipótesis propuesta no se cumple para todos los sintagmas fijos, como ocurre, por ejemplo, con sala de espera. En este caso concreto existen serias dudas sobre el proceso de formación del sintagma, pues no hemos podido verificar si se fijó en la norma (colocación) o si surge por la necesidad de nombrar por primera vez una realidad ontológica en un ámbito especializado (CS).

En cualquier caso, la validez de esta hipótesis es aplicable únicamente al estudio llevado a cabo en este artículo, que posee limitaciones debido a lo reducido del corpus y a la tipología textual escogida. No obstante, creemos que esta investigación supone un pequeño avance para la diferenciación de los distintos tipos de sintagmas nominales existentes en la fraseología, es decir, colocaciones, locuciones y CS. Si bien es cierto que se hace necesario analizar un mayor número de sintagmas procedentes de una muestra amplia de tipologías textuales para valorar en su justa medida la hipótesis planteada aquí. 


\section{BIBLIOGRAFÍA}

Álvarez García, Érica. «Las unidades fraseológicas en los prospectos de medicamentos en inglés y español». Paremia, no 27, 2018, pp. 69-84.

Barrios Rodríguez, María Auxiliadora. Las colocaciones del español. Arco Libros, 2015.

Bosque Muñoz, Ignacio, Dir. REDES. Diccionario combinatorio del español contemporáneo. Editorial S.M., 2005.

Cela, Camilo José. La colmena. Editorial Noguer, 1979.

Clavería, Gloria, y Joan Torruella. «Formación de términos en los léxicos especializados de lengua española». Curso práctico sobre el procesamiento de la terminología, por Juan C. Sager, Fundación Germán Sánchez Ruipérez, 1993, págs. 315-344.

Corpas Pastor, Gloria. Manual de fraseología española. Editorial Gredos, 1996.

Delibes, Miguel. Cinco horas con Mario. Ediciones Destino, 1978.

Gálvez Vidal, Alba María. La función de las unidades fraseológicas en la novela española de posguerra: una herramienta hermenéutica, un recurso para la resistencia. Universidad de Murcia, Tesis Doctoral, 2018.

Gálvez Vidal, Alba Maria, y Marta Navarro Coy. «¿Es Carmen la misma persona cuando habla en inglés? La traducción de unidades fraseológicas en Cinco horas con Mario». Enfoques actuales para la traducción fraseológica y paremiológica: ámbitos, recursos y modalidades, editado por Germán Conde Tarrío, Pedro Mogorrón Huerta, Manuel Martí Sánchez y David Prieto GarcíaSeco, Centro Virtual Cervantes (Instituto Cervantes), 2015, págs. 129-142.

García-Page Sánchez, Mario. «En torno a la locución y la colocación: semejanzas y diferencias», I Seminario de Fraseología de la Universidad de Brasilia, 11-15 de octubre 2010, Brasilia, Conferencia.

García-Page Sánchez, Mario. «Hombre rana, hombre clave, ¿un mismo fenómeno?». Verba, n 38 , 2011, págs. 127-170.

García-Page Sánchez, Mario. Introducción a la fraseología española. Anthropos, 2008.

Martín Gaite, Carmen. Entre visillos. Ediciones Destino, 1992.

Molina Gómez, José Ramón. «Las unidades léxicas en español». Carabela, n 56, 2004, págs. $27-50$

Montoro del Arco, Esteban Tomás. «Relaciones entre morfología y fraseología: las formaciones nominales pluriverbales». Neologismo y morfología, editado por Ramón Almela Pérez y Esteban Tomás Montoro del Arco. Universidad de Murcia, 2008, págs. 121-146.

Osorio Olave, Gabriela, y Susana Serra Sepúlveda. «Colocaciones, compuestos sintagmáticos y locuciones nominales: hacia un intento de delimitación conceptual». Lenguas modernas, no 39, 2012, págs. 103-116.

Pamies Bertrán, Antonio. «De la idiomaticidad y sus paradojas». Nouveaux apports à l'étude des expressions figées, editado por Germán Conde Tarrío, Cortil-Wodon, InterCommunicaions \& E.M.E., 2006, págs. 173-204.

Pérez Vigaray, Juan Manuel. «Locuciones y compuestos nominales: aportaciones de Julio Casares al estudio de la formación de palabras». Philologica canariensia, nº 2-3, 1996-1997, págs. 295-310.

Real Academia Española (RAE). Nueva gramática de la lengua española. Espasa, 2009. 
Real Academia Española (RAE). DLE (Diccionario de la lengua española) (23 ${ }^{\mathrm{a}}$ Ed.). Real Academia Española, 2014, www.rae.es/. Acceso 07 febrero 2021.

Sanz Vicente, María Lara. Análisis contrastivo de la terminología de la teledetección. La traducción de compuestos sintagmáticos nominales del inglés al español. Universidad de Salamanca, Tesis Doctoral, 2011.

Seco, Manuel, Olimpia Andrés, y Gabino Ramos. Diccionario fraseológico documentado del español actual. Locuciones y modismos españoles. Editorial Aguilar, 2004.

Sevilla Muñoz, Manuel. «Las unidades fraseológicas del discurso científico-técnico y su traducción (inglés-español)». Enfoques actuales para la traducción fraseológica y paremiológica: ámbitos, recursos y modalidades, editado por Germán Conde Tarrío, Huerta Pedro Mogorrón, Manuel Martí Sánchez y David Prieto García-Seco, Centro Virtual Cervantes (Instituto Cervantes), 2015, págs. 239-253.

Solano Rodríguez, María Ángeles. «Las unidades fraseológicas del francés y del español: tipología y clasificación». Paremia, ${ }^{\circ}$ 21, 2012, págs. 117-128.

Toledo Báez, María Cristina, y Raquel Martínez Lorente. «Colocaciones, locuciones y compuestos sintagmáticos bilingües (español-francés) sobre diabetes en el corpus comparable Cordiabicom». Panace@, vol. 19, nº 47, 2018, págs. 106-114.

\title{
LOS LÍMITES DIFUSOS ENTRE COMPUESTOS SINTAGMÁTICOS, COLOCACIONES Y LOCUCIONES
}

\begin{abstract}
Desde un punto de vista formal, semántico y funcional, existen similitudes entre compuestos sintagmáticos (CS) y otros sintagmas fijos, como colocaciones y locuciones, por lo que no siempre es fácil diferenciarlos. Es posible encontrar un mismo sintagma clasificado como locución, colocación y CS en función de la obra lexicográfica o fraseográfica consultada (mano dura, por ejemplo). GarcíaPage (En torno a, «Hombre rana»), entre otros autores, ha mostrado su preocupación por estas similitudes; Osorio y Serra realizaron una propuesta para distinguir entre locuciones y CS; y Corpas (51) establece la diferencia entre colocaciones y locuciones según su proceso de fijación.

En este estudio, pretendemos delimitar el concepto de CS en comparación con colocaciones y locuciones desde un enfoque fraseológico, partiendo de la teoría de Pamies, quien considera los CS como unidades fraseológicas (UF). Para ello, planteamos dos criterios relacionados con la fijación de los CS: que se hayan acuñado de manera artificial debido a la necesidad de nombrar una realidad ontológica por primera vez y que esa necesidad surja en un ámbito especializado. Comprobamos la validez de estos dos criterios en un corpus de sintagmas fijos extraído de tres novelas españolas.
\end{abstract}

Palabras clave: compuesto sintagmático; locución; colocación; fraseología. 


\section{ZRÓŻNICOWANIE DELIMITACJI MIĘDZY ZWIĄZKAMI SYNTAGMATYCZNYMI, KOLOKACJAMI ORAZ LOKUCJAMI}

Streszczenie

Z formalnego, semantycznego i funkcjonalnego punktu widzenia istnieją podobieństwa między związkami syntagmatycznymi (CS) a innymi typami fraz, takimi jak kolokacje i zwroty, co powoduje, że nie zawsze łatwo je rozróżnić.

W niniejszej pracy zamierzamy wyznaczyć pojęcie CS w porównaniu z kolokacjami i zwrotami w ujęciu frazeologicznym, wychodząc od teorii Pamiesa, który traktuje CS jako jednostki frazeologiczne (FU). Aby to zrobić, proponujemy dwa kryteria związane z ustalaniem CS: że zostały one sztucznie ukute ze względu na potrzebę nadania nazwy strukturze ontologicznej po raz pierwszy i że potrzeba ta pojawia się w wyspecjalizowanej dziedzinie. Trafność tych dwóch kryteriów sprawdzamy w zbiorze fraz pochodzących z trzech hiszpańskich powieści.

Słowa kluczowe: związek syntagmatyczny; zwrot; kolokacja; frazeologia. 